\title{
An initial study into New Zealander's perceptions of vegetated landscapes in rural areas
}

\author{
T.G. PARMINTER ${ }^{1}$, R.M. FORD ${ }^{2}$, J.A. WILSON ${ }^{1}$, L.H. PARMINTER ${ }^{3}$ and H. ROTH ${ }^{1}$ \\ ${ }^{1}$ AgResearch, Ruakura Research Centre, PB 3123, Hamilton \\ ${ }^{2}$ Land and Food Resources, University of Melbourne, Victoria 3121 \\ ${ }^{3}$ Media Studies Dept, University of Waikato, PB 3105, Hamilton
}

terry.parminter@agresearch.co.nz

\begin{abstract}
This project was undertaken to examine how people in the North Island of New Zealand might evaluate a variety of rural and agricultural landscapes and the criteria that they used to make their assessment. Between November 2004 and March 2005 a convenience sample of 50 people were interviewed from around the Waikato, Auckland and Bay of Plenty. The interviewers asked people to sort and discuss 54 photos of natural landscapes containing a range of vegetation types. All the photos were standardised to a similar composition to assist in the comparisons. Each person being interviewed was asked to sort the photographs into categories reflecting their own criteria and then explain the categories. They were then asked to identify their most and least preferred categories. The most preferred vegetation types were the indigenous forest types which were considered "inspiring" and "attractive". Well grazed grasslands were moderately preferred as being "natural" and "well managed". Cropped areas were disliked by some people for being "over controlled". The least preferred were gorse blocks and regenerating scrubland which were considered "ugly" and "messy".
\end{abstract} Keywords: landscape, policy, ecology

\section{Introduction}

Section 6 of the Resource Management Act (RMA 1991) identifies five natural and physical resource priorities that must be addressed by all landowners and developers. The list includes "the protection of outstanding natural features and landscapes" and protection of "areas of significant indigenous vegetation and ... fauna". Like other sections of the RMA, these issues need to first be socially defined at a more local level. So it is up to our regional and local communities to determine what landscapes are considered to be "outstanding" and what vegetation should be treated differently because it is "significant".

Landscapes can be appreciated at a number of scales of human activity. They represent the diversity and patterns we observe in the physical form, structure and function of the environment being considered (Forman 1995). Landscapes can include the natural features, the built environment and abstract elements such as light, shade, beauty and threat. How we appreciate a landscape will depend upon how much we emphasise different aspects of form, structure and function, and the characteristics that we rely upon within each of these in making our evaluations (Ford \& Parminter 2006).

Our personal values and beliefs can mean that some people will prefer indigenous vegetation while other people will find exotic vegetation more attractive. Community norms about the importance of keeping properties tidy and cared for may mean for example, that people spray certain weeds (e.g. scotch thistle) and prune trees that, but for living up to other peoples' expectations, they would rather have left. Professional groups such as farmers will have their own expected ways of behaving and activities such as always trimming hedges in certain ways can have significant landscape effects (Egoz et al. 2001).

Knowing how different community groups might interpret the range of types of vegetation in New Zealand landscapes requires understanding their cognitive and cultural frameworks influencing how they evaluate landscapes. The literature available does not describe the visual cues that "unguided" people in New Zealand might use in identifying similarities and differences between vegetated landscapes, nor do they fully describe the relative basis of preference that people may have for different types of vegetation in comparable landscapes.

This study used personal interviews and photograph sorting to identify which vegetative landscapes people preferred and how they made their preferences. In this paper we report on the number and types of groups of vegetated landscapes that people compiled during the interviews.

\section{Methods}

The method selected for this study was designed to expose the range of decision making processes that individuals might use in assessing their landscape preferences (Clark \& Watson 2003). To obtain the information needed to create a landscape assessment scale, personal interviews with photo sorting and ranking were developed to describe people's reconstructions of their decision making processes. The 
task that people were given to complete was designed to achieve psychological realism rather than mundane (real-life) realism or experimental (task) realism (Gilbert et al. 1998).

For the photo sorting exercise, a total of 54 photographs of a variety of vegetative landscapes were printed and prepared with each photograph numbered for subsequent analyses. All the photos were gathered from the Waikato and Bay of Plenty Regions. They were all standardised to similar focal distances, perspectives, colour densities and structure of composition. As much as possible, the photos all had a pasture background matrix with vegetative patches and between $10 \%-20 \%$ sky either visible or implied (Forman 2006).

Between November 2004 and March 2005 a convenience sample of 50 people were interviewed from around the Waikato, Auckland and Bay of Plenty, including farmers, students, urban people and tourists. People were selected from existing data sets or industry contacts to represent a range of landscape values. The stakeholder groups were selected to provide diversity in the data, but were not considered to be representational enough (in number or selection criteria) to justify between group comparisons in this analysis (Clark \& Watson 2003, p212).

At the interviews, each person was asked to sort the photographs into categories reflecting their own preferences and then explain the categories and their preferences to the interviewer. The sorting method was intended to provide process information rather than being problem orientated (Gilbert et al. 1998). Participants were asked to make judgements about which photos were similar and which photos were different in their own terms. The task stimulus was provided in their own home environment under conditions expected to trigger automatic responses (Gilbert et al. 1998). Any number of categories was possible and any number of photos could be allocated to each group. All the photos had to be used in the sorting process.

The photo-sorts were quantitatively analysed using cluster analysis to identify the photos which tended to be sorted in a similar way and the number of different groups being created. In the analysis, clustering was based upon group membership and the photos that people clustered together were further examined to establish any underlying pattern in group membership. The clustering was carried out using "group average linkage" and repeated with "general average linkage" to assess the stability of the results. When this method of analysis is effective, all the photos within a cluster will have high homogeneity and be most different from the photos sorted into clusters farthest away from them (Hair et al. 1998).
All the interviews were recorded and transcribed. The initial analysis described here has focussed upon understanding the way in which people categorised and described the vegetation and on identifying their preferences.

\section{Results}

People formed between three and 17 groups of photos. On average eight groups were formed (also the median number). A summary of the results is provided in Table 1 along with examples of the range of photographs that was used. The second column labels the type of vegetation fragment included in the photo. The third column contains the clustering results. Clustering can be assessed at varying levels of similarity from $0 \%-100 \%$. Low levels $(<30 \%)$ indicate that the photos were seldom in the same group together. High levels $(>70 \%)$ indicate that the photos were almost always in the same group together. In this study, the photos clustered in eight groups could be found together in these groups from $36 \%-99 \%$ of the time (Table 1). The fourth column identifies the groups from $1-8$. Some people split group 5 into two separate groups (a and b, Table 1) but combined groups 1 and 2 . This was less common that for the groups shown in Table 1. Only one photo had a poor relationship with any of the groups. This is the photo of an area after it has had pines harvested leaving only dead branches and other forest trash. This photo was linked to group 7 in 19\% of the interviews.

In their interviews, people described how they took three different approaches to evaluate the photos. Some people considered the different species and plant forms they contained e.g. native trees. Other people considered the different uses to which the plants could be put e.g. shelterbelts, and other people used their assessment of level of care associated with different types of vegetation e.g. the presence of weeds.

When asked about their preferences, people tended to say that they preferred the landscape photos containing bush remnants or isolated trees in grazed pasture to the other vegetation types. They declared a dislike of landscapes containing pasture weeds, woody regrowth, hedges and some types of wetlands.

The landscape types showing the most variability in peoples' preferences were the grazed grasslands, woody regrowth and wetlands, and manuka and flax. In these cases people were particularly influenced by the degree of care and attention that they assumed these areas were receiving. Well grazed pastures that were green and leafy were generally well liked by respondents. If they assumed that the presence of pasture weeds (e.g. thistles) and woody weeds (e.g. gorse) represented a neglectful owner, then they were more inclined to rank that landscape low in their preferences. If they assumed 
Table 1 Landscape perception results showing clustering of photos into eight groups. A high percent similarity indicates a high likelihood of group membership.

\begin{tabular}{|c|c|c|c|c|c|}
\hline $\begin{array}{l}\text { Photo } \\
\text { number }\end{array}$ & $\begin{array}{l}\text { Vegetation } \\
\text { fragment }\end{array}$ & $\begin{array}{l}\text { Cluster analysis } \\
\text { (similarity \%) }\end{array}$ & Groups 1-8 & Example Photo & \\
\hline 1 & Hedge & 71 & 1 & & \multirow[t]{4}{*}{ No. 10} \\
\hline 13 & Hedge & 44 & 1 & & \\
\hline 10 & Hedge & 75 & 1 & & \\
\hline 52 & Hedge & 35 & 1 & & \\
\hline 16 & Shelterbelt & 61 & 2 & & \multirow[t]{3}{*}{ No. 23} \\
\hline 23 & Shelterbelt & 41 & 2 & & \\
\hline 24 & Shelterbelt & 18 & 2 & & \\
\hline 7 & Wetland & 66 & 3 & & \multirow{6}{*}{ No. 27} \\
\hline 11 & Wetland & 68 & 3 & & \\
\hline 20 & Wetland & 41 & 3 & & \\
\hline 8 & Gorse & 80 & 3 & & \\
\hline 18 & Gorse & 74 & 3 & & \\
\hline 42 & Gorse & 56 & 3 & & \\
\hline 27 & Regeneration & 50 & 3 & & \multirow{8}{*}{ No. 26} \\
\hline 40 & Rushes & 49 & 3 & & \\
\hline 47 & Pampas & 25 & 3 & & \\
\hline 14 & Grassland & 95 & 4 & & \\
\hline 26 & Grassland & 79 & 4 & & \\
\hline 50 & Grassland & 63 & 4 & & \\
\hline 43 & Grassland & 54 & 4 & & \\
\hline 22 & Thistles & 4 & 4 & & \\
\hline 2 & Kahikatea bush & 71 & $5 a$ & & \multirow{7}{*}{ No. 32} \\
\hline 6 & Bush fragment & 91 & $5 a$ & & \\
\hline 32 & Bush fragment & 95 & $5 a$ & & \\
\hline 38 & Bush fragment & 88 & $5 a$ & & \\
\hline 44 & Bush fragment & 71 & $5 a$ & & \\
\hline 30 & Bush fragment & 58 & $5 a$ & & \\
\hline 12 & Flowering native tree & 38 & $5 a$ & & \\
\hline
\end{tabular}




\begin{tabular}{|c|c|c|c|c|c|}
\hline $\begin{array}{l}\text { Photo } \\
\text { number }\end{array}$ & $\begin{array}{l}\text { Vegetation } \\
\text { fragment }\end{array}$ & $\begin{array}{l}\text { Cluster analysis } \\
\text { (similarity \%) }\end{array}$ & Groups 1-8 & Example Photo & \\
\hline 33 & Shelterbelt & 58 & $5 a$ & & \multirow{7}{*}{ No. 36} \\
\hline 34 & Bush fragment & 37 & $5 a$ & & \\
\hline 5 & Planted kauri & 47 & $5 b$ & & \\
\hline 9 & Regeneration & 58 & $5 b$ & & \\
\hline 36 & Regeneration & 76 & $5 b$ & & \\
\hline 39 & Regeneration & 67 & $5 b$ & & \\
\hline 49 & Regeneration & 48 & $5 b$ & & \\
\hline 51 & Wetland & 16 & $5 b$ & & \multirow{8}{*}{ No. 45} \\
\hline 17 & Isolated tree & 67 & 6 & & \\
\hline 45 & Isolated trees & 60 & 6 & & \\
\hline 35 & Planted kahikatea & 66 & 6 & & \\
\hline 48 & Isolated trees & 40 & 6 & & \\
\hline 25 & Isolated trees & 72 & 6 & & \\
\hline 29 & Isolated trees & 54 & 6 & & \\
\hline 37 & Isolated trees & 5 & 6 & & \\
\hline 4 & Trash from harvested pines & 19 & - & & \multirow{7}{*}{ No. 53} \\
\hline 19 & Woodlot & 49 & 7 & & \\
\hline 28 & Planted manuka & 49 & 7 & & \\
\hline 41 & Planted totara & 57 & 7 & & \\
\hline 46 & Pines & 79 & 7 & & \\
\hline 53 & Pines & 76 & 7 & & \\
\hline 54 & Pines & 37 & 7 & & \\
\hline 21 & Woodlot & 9 & 7 & & \multirow{4}{*}{ No. 15} \\
\hline 3 & Maize & 96 & 8 & & \\
\hline 15 & Maize & 99 & 8 & & \\
\hline 31 & Pumpkins & - & 8 & & \\
\hline
\end{tabular}


that these areas of regrowth represented a deliberate action on the part of the owner to restore areas of native bush, they were likely to rate it higher in their preferences.

\section{Discussion and Conclusions}

The results indicated that even without clear guidance about how to do so, people tended to use a limited number of categories for assessing vegetated landscapes. They clearly distinguished between landscapes with functional differences e.g. for grazing or cropping. Landscapes with indigenous vegetation tended to be grouped together.

Areas of remnant native bush within agricultural landscapes showed a high degree of consistency in people's preferences. Grazed areas containing isolated trees or clumps of trees to create a park-like appearance were also liked. Well grazed pastures were preferred to soft weeds, woody regrowth and rank wetlands, particularly if the wetlands contained willows. At this stage we have not identified the underlying psychological drivers of their preferences. These will come from further analysis.

The results are consistent with there being good social support for protecting areas of existing remnant vegetation in agricultural landscapes. However, landowners allowing areas of previously grazed land to regenerate towards indigenous forest may be considered by their peers to be poor land managers "encouraging weeds". There is no indication in this study to suggest how long such a phase may last, and if the level of approbation depends upon how well the rest of their property is being cared for. Research has already suggested that this could also be a limitation for some examples of organic farming in traditional agricultural regions (Egoz et al. 2001).

Environmental protection agencies such as the Queen Elizabeth II National Trust (QE II Trust) work with landowners to assist them to protect areas of natural heritage. These results reinforce the role that the QE II Trust has working with landowners to ensure the ongoing maintenance of covenanted areas, so that they do not appear to be neglected for people living elsewhere in their local community.

The wetland photos used in this study did not show obvious areas of surface water or ponding. Respondents only had the vegetative content to use as a guide in their assessment. When these areas were associated by people with neglect rather than deliberate preservation, they were not preferred above other landscape types, including well grazed pastures. This suggests that activities to promote the preservation of wetlands on private land for their ecological contributions may run counter to generally held landscape preferences.

The study has highlighted the value of continued research into individual decision maker's preferences for different landscape types. It also has shown the importance of understanding social norms around landscapes and property management. The results of such research in the future may assist Councils, communities, and rural professionals negotiate areas that may be of outstanding and significant value to communities. These areas will not only need to be preserved but also managed to ensure their continued contribution to our social identity as communities and to us as a country.

\section{ACKNOWLEDGEMENTS}

We acknowledge the time and energy provided by the many community participants in this research and the ongoing support provided by staff in Landcare Research Ltd. The project would not have been possible without funding from the Foundation of Research Science and Technology. Our thanks to Martin Upsdell for carrying out the cluster analyses.

\section{REFERENCES}

Clark L.A.; Watson D. 2003. Constructing validity: basic issues in objective scale development. pp 207-232 In: Methodological issues and strategies in clinical research, third edition. Ed. A.E. Kazdin American Psychological Association, Washington.

Egoz, S.; Bowring, J.; Perkins H.C. 2001. Tastes in tension: form, function, and meaning in New Zealand's farmed landscapes. Landscape and Urban Planning 57: 177-196.

Ford, R.M.; Parminter T.G. 2006. A review of studies into landscape preferences. Client Report for NZ Foundation of Research Science and Technology. AgResearch, Hamilton, New Zealand.

Forman, R.T.T. 1995. Land mosaics: the ecology of landscapes and regions. Cambridge University Press (2006 printing), Cambridge.

Gilbert D.T.; Fiske S.T.; Lindzey G. 1998. The handbook of social psychology, volume 1, fourth edition. McGraw-Hill, New York.

Hair, J. F.; Anderson, R.E.; Tatham R.L.; Black W.C. 1998. Multivariate data analysis. Prentice-Hall International, Upper Saddle River, New Jersey.

Resource Management Act, 1991. No 69. March 2005. New Zealand Government, Wellington. 